\title{
Un enfoque realista para las formalidades del derecho de autor ${ }^{\mathrm{I}}$
}

\author{
A realist approach to copyright law's formalities
}

MICHAELW. CARROLL

American University, Washington College of Law, Estados Unidos

RESUMEN Rechazando la historia convencional de que las formalidades en el derecho de autor fueron abolidas por el Convenio de Berna, este artículo demuestra que los sistemas de formalidades administrados privadamente juegan un papel importante, a nivel mundial, en la administración del derecho de autor. Efectivamente, deben hacerlo, porque el derecho de autor está diseñado para ser el soporte de una estructura de transacciones, que requiere que los titulares —en búsqueda de atraer socios de licencias - se sometan a algún paso formal para identificarse a ellos mismos y a las obras en las que tengan un interés jurídico o de usufructo. Analizando el escenario de los sistemas de formalidades públicos y privados, tanto obligatorios como voluntarios, este artículo sostiene que: I) en virtud del Convenio de Berna, los gobernantes nacionales conservan una mayor autoridad política para imponer ciertos requisitos formales en los titulares, que la sostenida por aquellos con una comprensión formalista de las formalidades públicas; 2) los sistemas privados de formalidades son amplios y de gran importancia económica, pero en muchos casos no son interoperables entre sí, ni con registros voluntarios u

I. El autor agradece a Peter Jaszi por proporcionar sugerencias útiles y a Alan deLieve y Alexandra El-Bayeh por su asistencia en la investigación. 
otros sistemas voluntarios de formalidades públicas; y 3) las autoridades deben utilizar una combinación de enfoques para mejorar el funcionamiento de los sistemas de formalidades tanto públicos como privados, promoviendo o requiriendo transparencia, eficiencia e interoperabilidad en su diseño y administración.

PALABRAS CLAVE Derecho de autor, formalidades, Convenio de Berna, Estados Unidos.

ABSTRACT Rejecting the conventional story that formalities in copyright law were abolished by the Berne Convention, this Article demonstrates that privately administered systems of formalities play a significant role in the administration of copyright law worldwide. Indeed, they must because copyright is designed to support a transaction structure which requires rights holders who seek to attract licensing partners to go through some formal step to identify themselves and the works in which they have a legal or beneficial interest. Canvassing the landscape of mandatory and voluntary public and private systems of formalities, this article argues that: (I) national policymakers retain more policy authority under Berne to impose certain formal requirements on rights holders than those with a formalist understanding of public formalities argue; (2) private systems of formalities are extensive, economically significant, but are not interoperable with each other in many cases and with voluntary registries and other voluntary public formalities systems; and (3) policymakers should use a mix of approaches to improve the functioning of both public and private formalities systems by promoting or requiring transparency, efficiency, and interoperability in their design and administration.

KEYWORDS Copyright, formalities, Berne Convention, United States.

\section{INTRODUCCIÓN}

¿Hacia qué lugar transitan las formalidades en el derecho de autor? En I989, Estados Unidos eliminó los requerimientos formales para obtener la protección de copyright dentro de sus fronteras, ${ }^{2}$ de modo que

2. Véase la Ley de Aplicación del Convenio de Berna, Pub. L. Io०-568, I02 Stat. 2853 ( 1989), que modificó una serie de secciones del Título I 7 de Código de los Estados Uni- 
el país podría ser parte del Convenio de Berna para la Protección de las Obras Literarias y Artísticas. ${ }^{3}$ Ciertos sectores triunfalistas le dieron la bienvenida a esta decisión, calificándola como un importante paso adelante. ${ }^{4}$ Estados Unidos abandonó prospectivamente su longeva política de administrar los derechos de autor como un sistema de inclusión optativa para autores y editores, y subsecuentemente estuvo de acuerdo en «restaurar» el copyright a autores extranjeros, que habrían recibido la protección de haber cumplido con estos requerimientos formales. ${ }^{5} \mathrm{La}$ narrativa triunfalista visualiza la adopción de estas obligaciones internacionales por parte de Estados Unidos, como la aceptación de un enfoque deontológico al derecho de autor, haciendo necesario un formalismo estricto para juzgar qué cuenta como una formalidad, y qué es permisible bajo el Convenio de Berna. ${ }^{6}$

Esta comprensión formalista de la obligación de antiformalidad establecida en el artículo 5.2 del Convenio, posteriormente incorporada al Acuerdo sobre los Aspectos de los Derechos de Propiedad Intelectual relacionados con el Comercio (Acuerdo sobre los ADPIC), ${ }^{7}$ tiene como objetivo reducir el espacio político para el desarrollo o regulación de requerimientos formales impuestos a los autores, en el ejercicio o goce de sus derechos en virtud del copyright (Ficsor, 2006: 48). Sin embargo, en esta era de redes digitales y globalización creciente, la visión formalista se encuentra bajo presión, al hacerse más evidentes los costos de un co-

dos, para eliminar los requisitos de incluir un aviso de copyright en las copias publicadas, en el depósito de una copia, y en el registro de una reclamación al derecho de autor, previo a la interposición de una demanda por infracción.

3. Convenio de Berna para la Protección de las Obras Literarias y Artísticas (Convenio de Berna). Todas las citas al Convenio de Berna están referidas al «Acta de París», adoptada el 24 de julio de I97 I, y a la cual Estados Unidos adhirió el I de marzo de I989.

4. En general, véase Austin (2005), Karp (I995), Levine (I995) y Perlmutter (I995).

5. Véase Golan v. Holder, I32 S. Ct. 873 (2012), donde se analiza y describe la restauración constitucional de los derechos de autor, en la Copyright Act de Estados Unidos.

6. Véanse Austin (2005), Karp (I995), Levine (I995), Perlmutter (I995) y también Ficsor (2006: 48), quien argumenta que la disposición antiformalidades prohibiría que un titular presunto de licencia obligatoria recurra a una cláusula de exclusión.

7. Acuerdo sobre los Aspectos de los Derechos de Propiedad Intelectual relacionados con el Comercio, de la Organización Mundial de Comercio. 
pyright automático. ${ }^{8}$ Un grupo de académicos y políticos han empezado a explorar formas para ampliar el espacio político en el que las formalidades del derecho de autor pueden remodelarse y desplegarse. ${ }^{9}$

Este artículo adhiere a la postura general que está a favor de fortalecer las formalidades públicas, pero sostiene, en base a la tradición del realismo jurídico, que esta proliferación formalista ha constreñido más de lo que debería la discusión política en torno a la reintroducción de formalidades. Al hacerlo, asume familiaridad con los debates acerca del formalismo y realismo jurídico, ${ }^{\text {10 }}$ y se basa en el análisis habitual de la distinción

8. Véanse, por ejemplo, Van Gompel (20II: I-8); Lessig sugiere que los titulares de derechos de autor deben soportar alguna pequeña carga, al menos para renovar su protección (2004: 292-293); Dusollier (201 I: I03-I95) explica la necesidad de un sistema de formalidades eficiente, diseñado para maximizar el fin comercial del derecho de autor; Gibson (2005: 2I2-24I) propone cambios políticos para ayudar a los autores a proteger sus obras en la era digital, a través de nuevos tipos de formalidades públicas o privadas; Ginsburg (20IO: 3 II-3 I7) sugiere un cambio en la política respecto a las formalidades para la inscripción de las transferencias de títulos, que ayudaría a los autores a transferir su trabajo con mayor seguridad; Sprigman (2004: 545-568) propone posibles nuevas formalidades de estilo, que lleven de vuelta a un pasado utilitarista sin rechazar el Convenio de Berna; véase también Pallante (2013: I4I5-I4I8): «Las formalidades son interesantes porque, si se implementan prudentemente, tienen la capacidad de aliviar frustraciones, de incentivar el buen comportamiento, y de crear una administración más racional de la ley, todo lo cual es bueno para los autores»; Glushko Samuelson Intellectual Property Law Clinic (2005: 2-3) en la indagación sobre el problema de las «obras huérfanas» realizado por la United State Copyright Office, Library of Congress, describe la conexión entre la ausencia de formalidades y la presencia del problema de obras huérfanas; De la Durantaye (20I I: 236-237) realiza un estudio sobre literatura en el marco del problema de las obras huérfanas.

9. Veáse Van Gompel (20II: 288-296), quien sugiere que las formalidades sean reintroducidas en atención a los derechos económicos de los dueños del derecho de autor. Véase también Dusollier (20II: I03-I05), Gibson (2005: 2I2-24I), Ginsburg (2010: 3 I7), Lessig (2004: 292-293) y Sprigman (2004: 545-568).

ıо. Como muchos lectores saben, el «formalismo jurídico» y el «realismo jurídico» son etiquetas utilizadas para graficar una variedad de enfoques jurisprudenciales para la interpretación y aplicación de la ley. Leiter (2010) ofrece una visión general de los enfoques, y un análisis de las discrepancias en torno a ellos; Quevedo (1985) entrega una buena historia de los dos enfoques. Para el propósito actual, unas cuantas simples observaciones deberían bastar para establecer una base desde la que se pueda medir la interpretación y el entendimiento de la disposición antiformalidades del Convenio de Berna y las formalidades propiamente tales, dependiendo si se tiende más hacia el formalismo o el realismo. 
entre lo público/privado ${ }^{\text {II }}$ y en las aproximaciones formalistas/funcionalistas $^{12}$ de la interpretación y aplicación de la ley. Cuando se plasma en

I I. El discurso jurídico que distingue entre «lo público»y «lo privado» lo hace en más de una forma, pero la más común es la distinción entre actores gubernamentales y no gubernamentales, como se refleja en los términos "derecho público» y «derecho privado», por ejemplo, en Horwitz ( I 982). Esta versión de la distinción ha sido sujeto de una fulminante crítica, por ejemplo, Kennedy (I982: I349-I357) señala: «Siguiendo estas líneas de similitud y diferencia, simplemente se pierde la capacidad propia para tomar en serio la distinción público/privado como una descripción, como una explicación, o como la justificación de cualquier cosa». ¿Por qué, por ejemplo, debería una corporación, cuya «personalidad» jurídica depende del gobierno, ser tratada como una entidad "privada»? Numerosos estudiosos críticos han también demostrado las formas en que la esfera "privada» es, propiamente, tema de política pública. Cf. Turkel (I988: 80I-802).

I2. Véase, en general, Cohen (I935) usando, a modo de ejemplo, la cuestión jurídica relativa a la ubicación geográfica de una corporación para propósitos jurisdiccionales, como una cuestión susceptible de ilustrar el enfoque. Los enfoques formalistas versus funcionalistas de interpretación jurídica conducen a interesantes resultados cuando se aplican a la pregunta de qué es lo que desencadena el artículo 5.2 del Convenio de Berna, y su primo del Acuerdo sobre los ADPIC: el artículo 9.I (que incorpora casi todo el contenido del Convenio de Berna al Acuerdo). Un enfoque formalista aplicaría la disposición sólo a las formalidades públicas, mientras que un enfoque funcionalista podría imponer responsabilidad a un Estado miembro si dentro de su territorio un autor no tuviera otra opción práctica más que la de participar en un sistema de formalidades privadas para ejercer o gozar sus derechos económicamente. Véase Van Gompel (20II: 206-208). Este problema ya ha surgido respecto a la participación obligatoria en la gestión colectiva de derechos. Respecto a la interpretación de «ejercicio» y «goce», algunos formalistas tratarían a cualquier condición formal establecida para la obtención, licenciamiento, o ejercicio de derechos como una formalidad prohibida. Véanse, por ejemplo, las Actas de la Conferencia Internacional para la protección de los derechos de autor, reunión de Berna, 8 al I9 de septiembre de I884, revisada en Ricketson y Ginsburg (2006: parágrafo 6.IO2): «todo lo cual debe cumplirse con el fin de garantizar que los derechos del autor en relación con su trabajo, puedan llegar a existir». Otros podrían basarse en una distinción formal entre derechos y recursos jurídicos, y aplicar la prohibición sólo a las condiciones previas establecidas para la obtención y licenciamiento de derechos. Véase eBay Inc. v. MercExchange, L.L.C., 547 U.S. 388,392 (2006), donde se distingue entre derechos y recursos jurídicos en el contexto de una medida cautelar por infracción de patente: «la creación de un derecho es distinta del otorgamiento de recursos para las violaciones de ese derecho»; cf. Sprigman (20I3: I 565-I 573). Un funcionalista podría concluir que, aunque el sometimiento a condición de la capacidad del autor para obtener, licenciar, o ejercer derechos era una formalidad - de aquellas trivialmente fáciles de cumplir-, ésta no se elevaría al nivel de una que deteriore la capacidad de los autores para ejercer o gozar derechos. 
el contexto actual, la distinción público/privado oscurece en gran medida a los numerosos sistemas de formalidades administrados de manera privada, que son cumplidos y respetados por autores de los más variados campos creativos, como veremos más adelante. Formalmente, como instrumentos de derecho internacional público, el Convenio de Berna y el Acuerdo sobre los ADPIC regulan formalidades "públicas», promulgadas a través de los procesos legislativos formales de un Estado miembro. Aun así, estos instrumentos dejan simultáneamente espacio abierto para las formalidades «privadas» impuestas por actores, como las entidades de gestión colectiva, que dependen en parte del poder estatal para funcionar. ${ }^{\mathrm{I} 3}$ La discusión política relativa al rol de las formalidades en los derechos de autor, no debería ser constreñida al enfocarse únicamente en el papel que juegan los requerimientos públicos y la administración pública, sino también tener en cuenta a los actores privados que imponen y se valen de requerimientos formales, afectando el goce y ejercicio de los derechos de autor. Interesantemente, desarrollos recientes en la Organización Mundial de la Propiedad Intelectual (OMPI) apoyan este argumento y exponen un enfoque realista para elidir la distinción público/ privado. ${ }^{\mathrm{I}}$ En sustento de su proyecto temático de propiedad industrial y dominio público, la OMPI encargó estudios cubriendo tanto los sistemas de formalidades públicas como privadas, para proporcionar una imagen realista de la catalogación de los derechos de autor en el entorno digital. ${ }^{\text {I5 }}$

I3. A fines del siglo XIX y a lo largo del siglo XX, referirse a los requisitos formales impuestos por esos actores privados como «formalidades de derecho de autor» habría sido considerado incoherente, porque esos requisitos, respecto a la limitación del Convenio de Berna, están en el otro lado de la distinción público/privado.

I4. Cf. las 45 recomendaciones adoptadas en el marco del Programa de la OMPI para el Desarrollo, disponibles en <http://bit.ly/ıCH9qaj>. Por ejemplo, la Categoría A núm. 9 de las Recomendaciones Adoptadas trajo una medida de realismo jurídico al interés de la organización en las formalidades de derecho de autor. Véase también nota al pie 30, donde se discuten los estudios de la OMPI sobre los servicios de catalogación privada de copyright y su interacción con los sistemas de formalidades públicas. Éstas son buenas noticias. Específicamente, las encuestas y estudios de la OMPI sobre formalidades de derecho de autor reconocen que las formalidades privadas están apropiadamente dentro del alcance del Convenio de Berna y que la interacción entre formalidades públicas y privadas es un tema que merece atención.

I 5. Como parte del proyecto temático sobre propiedad intelectual y dominio público, que se contempla en la Agenda de la OMPI para el Desarrollo, también se está 
Los requerimientos formales, tales como la publicación con aviso, registro, depósito y renovación o mantención, sirven para una variedad de funciones que se condicen con la principal meta económica del derecho de autor, ésta es, proveer a los autores, editores y a sus inversores, con las ganancias potenciales por obras culturalmente atractivas (Van Gompel, 20I I: I 5-5I). En particular, las formalidades requieren que los titulares de derechos proporcionen potenciales compañeros de transacción, con la suficiente información para identificar al dueño del copyright, de manera que puedan iniciarse las conversaciones relativas a la concesión de licencias o adquisición de derechos (Van Gompel, 20 I I: I 8-I9). Dándose cuenta de que el artículo 5.2 del Convenio de Berna y el artículo 9.I del Acuerdo sobre los ADPIC han eliminado las formalidades de derecho público, la perspectiva realista cambia el enfoque de la política, a uno que se centra en cómo esos sujetos de regulación del derecho de autor pueden crear sustitutos privados para esas formalidades públicas (Van Gompel, 20I I: 206-208). Desde esta perspectiva, el espacio alguna vez ocupado por un sistema de formalidades administrado por funcionarios públicos, antes que abandonado, ha sido más bien privatizado. ${ }^{16}$

Específicamente, este artículo sostiene que los funcionarios públicos tienen un margen para mejorar el funcionamiento de las formalidades en el sistema de derechos de autor, de dos modos: r) usando la flexibilidad disponible dentro del marco internacional existente para aumentar el papel de las formalidades administradas públicamente; y 2) reconociendo los sistemas de formalidades privadas conducidos por las entidades de gestión colectiva, como también trabajando para mejorar la interoperabilidad y transparencia en estos sistemas a través de una mezcla

elaborando un estudio sobre sistemas y prácticas existentes en el ámbito privado para la catalogación de obras protegidas por el derecho de autor. Este estudio abarcará la catalogación del derecho de autor, incluida la aplicación de la información de gestión de derechos (RMI, por su nombre en inglés) que utilizan entidades tales como las entidades de gestión colectiva de derechos o el sistema Creative Commons, y examinará el modo en que los sistemas identifican, o podrían contribuir a identificar, los contenidos que estén protegidos o que pertenezcan al dominio público. Cf. OMPI, «Catalogación y registro del derecho de autor», disponible en <http://bit.ly/1HDCGeM>.

I6. Van Gompel (20I I: 206-208); Pallante (20I3: I42I) se refiere al atractivo de hacer interoperable la inscripción en la base de datos de la U.S. Copyright Office con las bases de datos de inscripción administradas por las entidades de gestión colectiva de derechos. 
de cooperación pública/privada y regulación pública. En ambos frentes, los funcionarios públicos deberían considerar el rol de los estándares técnicos como fuerza reguladora, tanto en los sistemas públicos como privados de formalidades, y deberían trabajar para asegurar que esos estándares de decisión reflejen las valoraciones públicas.

La mayoría de la literatura existente y emergente se centra en mejorar el papel de las formalidades administradas públicamente, ${ }^{17}$ así que en tal sentido este artículo ofrecerá sólo unas cuantas recomendaciones. En cambio, se enfoca principalmente en el rol y la regulación de las formalidades privadas, y en la importancia de los estándares técnicos cuando se trata de minimizar los costos y maximizar los beneficios que ofrecen las tecnologías digitales, en el diseño e implementación de formalidades de derecho de autor.

\section{REVITALIZANDO LAS FORMALIDADES PÚBLICAS}

Esta parte critica la narrativa formalista sobre las formalidades públicas y proporciona apoyo adicional para aquellos que sostienen que los funcionarios públicos podrían reintroducir legalmente algunas formalidades públicas obligatorias a nivel nacional, dentro de la estrechez de las disposiciones antiformalidad presentes en el Convenio de Berna y el Acuerdo sobre los ADPIC. La narrativa formalista ha pasado por alto en gran parte las funciones beneficiosas que las formalidades pueden realizar - y han realizado-, a pesar de que históricamente las implementaciones han tenido algunas deficiencias. ${ }^{18}$ Esta narrativa también exagera las restricciones que impondría una construcción del derecho de autor desde la óptica de los derechos humanos, en la expansión o reintroducción de formalidades públicas. ${ }^{19}$ En relación con esto, mientras la

I7. Véanse Dusollier (20II: I03-I05), Gibson (2005: 2I 2-24I), Ginsburg (2010: 3 I 7), Lessig (2004: 292-293), Sprigman (2004: 545-568) y Van Gompel (20I I: 288-296).

I8. Sprigman (2004: 545-568) reconoce las deficiencias en la rigidez de los requisitos de las formalidades y propone un sistema alternativo más flexible; Pallante (2OI3: I4I 5I4I 8) articula los beneficios de formalidades diseñadas prudentemente.

I9. Véase Van Gompel (20II: 267-280), quien demuestra que los derechos basados en la personalidad pueden ser, y están, sujetos a formalidades en Europa; véase también Sprigman (2004: 543), quien señala que «el grado en que las formalidades son inconsistentes con el copyright basado en derechos naturales es fácilmente exagerado». 
interpretación formalista de las disposiciones antiformalidad del Convenio de Berna y el Acuerdo sobre los ADPIC se fundamente en el constructo de los derechos humanos, está en contradicción con la historia tanto a nivel nacional como internacional. La doctrina reciente deja en claro que estas disposiciones pueden comprenderse de mejor forma, en tanto reflejan una reacción a las complejidades de un mosaico cambiante de formalidades nacionales, en lugar de un rechazo total de ellas. ${ }^{20}$ Esta doctrina también clarifica que las restricciones del Convenio de Berna y del Acuerdo sobre los ADPIC no tienen un alcance tan amplio, como se ha asumido comúnmente. En particular, existen oportunidades para reintroducir formalidades públicas que podrían favorecerse de las nuevas tecnologías para racionalizar su administración, y tecnologías que podrían ayudar a realizar una función de filtrado respecto a las obras publicadas en internet. Consecuentemente, es tiempo propicio para que los funcionarios públicos piensen creativamente cómo las formalidades públicas podrían expandirse, remodelarse o reintroducirse para permitir que el derecho de autor promueva sus objetivos políticos de una mejor forma.

Uno de los objetivos que se buscan al conceder copyright a un autor, o al menos a los derechos económicos en las obras de su autoría, es apoyar una estructura de transacciones, en la que éste tenga la oportunidad de ser recompensado por las obras que tengan un atractivo popular. ${ }^{21}$ Esta estructura de transacciones se basa en algunas de las funciones que tradicionalmente tuvieron las formalidades de derecho de autor, en cuanto a dar aviso sobre la identidad del (los) autor(es), la(s) obra(s), y de otra información relevante para las potenciales partes de una transacción relativa a los derechos exclusivos en la(s) obra(s). ${ }^{22}$

20. Véanse Van Gompel (20II), Gervais (20I0a, 20I0b, 20II), Ficsor (20I0), Helfer (2010) y Van Gompel (2010).

2I. «En nuestra prisa para difundir noticias, no hay que olvidar que los redactores de la Constitución propusieron que el derecho de autor en sí mismo sea el motor de la libre expresión. Mediante el establecimiento de un derecho comerciable al uso de la propia expresión, el copyright proporciona el incentivo económico para crear y difundir ideas.» Harper \& Row Publishers, Inc. v. Nation Enters, 47I U.S. 539, 558 (I985); véase también Sprigman (2004: 523-528), quien argumenta, en parte, a favor de formalidades renovadas para apoyar el intercambio de información relacionada con transacciones.

22. Van Gompel (20II: 47-49) describe el papel que las formalidades podrían tener en el suministro de información. 
En sus propios términos, la narrativa formalista es problemática en su núcleo, porque se requiere algún tipo de función de aviso y registro para que los autores reciban los beneficios económicos completos que el derecho de autor está diseñado para suministrar. Por otra parte, al menos en Estados Unidos, la ley concede beneficios económicos privados a los autores, a fin de lograr un objetivo público y más amplio. ${ }^{23}$ Esta sola observación debería situarnos en una postura interpretativa más generosa respecto al potencial para implementar formalidades públicas bajo el marco internacional.

Otras dos observaciones refuerzan aún más este punto. Primero, la narrativa formalista interpreta erróneamente las obligaciones de derechos humanos, al confundir los derechos legales con las opciones para obtener u ejercer estos derechos. ${ }^{24}$ La legislación de los derechos humanos no consolida un principio general que impida a un gobierno determinado tratar a los derechos civiles y políticos como una opción para obtener y ejercer derechos, en lugar de como un otorgamiento ab initio en todos los casos. ${ }^{25}$ Por ejemplo, el derecho a voto está considerado entre los más centrales derechos políticos que poseen los ciudadanos de una democracia, y los gobiernos todavía requieren rutinariamente de potenciales votantes para cumplir con una formalidad —el registro-, antes de que puedan ejercer o gozar este derecho. ${ }^{26}$

Segundo, la narrativa formalista está en contradicción con la historia de la obligación antiformalidades del Convenio de Berna, y también lo está respecto a cómo esta obligación debería ser interpretada a la luz de dicha historia. Trabajos recientes de Stef van Gompel, Daniel Gervais,

23. «El efecto inmediato de nuestra ley de derechos de autor es asegurar una retribución justa por la labor creativa de un 'autor'. Pero el objetivo final es, a través de este incentivo, estimular la creatividad artística para el bien común general.» Twentieth Century Music Corp. v. Aiken, 422 U.S. I 5 I, I 56 (I975).

24. «El grado en que las formalidades son inconsistentes con el copyright basado en derechos naturales es fácilmente exagerado» (Sprigman, 2004: 543).

25. Van Gompel (20I I: 267-280) demuestra que los derechos basados en la personalidad pueden ser, y están, sujetos a formalidades en Europa.

26. Carroll (2006: 879) escribe sobre este punto en el contexto de si los derechos legales deben ser tratados como derechos propiamente tales, o como opciones reales para adquirir derechos. 
y otros ${ }^{27}$ demuestran que los creadores de las disposiciones antiformalidades respondieron a una situación en la que los autores y editores se enfrentaban a formalidades excesivamente engorrosas, operando en un mercado cada vez más internacional de obras con copyright. Algunos triunfalistas del derecho de autor minimizan o ignoran esta historia estratégicamente. ${ }^{28}$ Sin embargo, esgrimir argumentos deontológicos para propósitos utilitaristas es, por lo general, contraproducente. ${ }^{29}$ Los intentos por tratar las disposiciones antiformalidades del Convenio de Berna como un reconocimiento de los derechos humanos de los autores, en vez de como una respuesta situacionalmente pragmática a las dificultades administrativas, siguen este patrón.

Doctrina reciente se ha desarrollado bajo la premisa de que se requiere un cierto nivel de formalidades para dar soporte a una estructura de transacciones relacionada con los derechos exclusivos en obras de autor, y que la prohibición internacional de ciertas formalidades públicas como condición previa del ejercicio y goce del derecho de autor está basada en objeciones pragmáticas que pueden ser revisadas a la luz de nuevas circunstancias. ${ }^{3 \circ}$ Es bienvenido este interés académico en un enfoque más vigoroso a las formalidades públicas, porque el sistema actual deja un considerable margen para mejoras.

La OMPI, en su Agenda para el Desarrollo, proporciona razones para prestar una renovada atención a las funciones beneficiosas que realizan

27. Van Gompel (20II), Gervais (20I0a, 20I0b, 20II), Ficsor (20I0), Helfer (20I0) y Van Gompel (2010).

28. Hatch (I989: I92-195) describe el problema de las formalidades como "esotérico e innecesario» en el retraso sufrido por Estados Unidos en su adhesión al Convenio de Berna; y Stanton (I990: I69) describe el retraso en la aprobación del Convenio de Berna como consecuencia de un acalorado debate sobre las formalidades.

29. Seidman (I984: 339-340) demuestra las inherentes contradicciones en el uso de la culpa moral como una estrategia utilitarista para el control del crimen.

30. Sprigman (2004: 545-546) explica que la innovación tecnológica podría hacer más factible la reintroducción de formalidades; Ginsburg (2010: 316-3I7) describe tipos de formalidades que pueden existir y que todavía existen bajo el Convenio de Berna; Gibson (2005: 2I 2-24I) discute la necesidad de que las formalidades equilibren los derechos legales en el derecho de autor; Gervais (20II: 3-5) discute la historia de la regulación antiformalidades en el Convenio de Berna y el grado en que las formalidades todavía existen en el derecho de autor; y Van Gompel (20I I: I93-2I4) describe el actual uso de las formalidades bajo el Convenio de Berna. 
las formalidades públicas de derecho de autor. Específicamente, en lo que respecta al registro, éstas incluyen el otorgamiento de medios públicos para: I) hacer valer las reclamaciones de autoría y propiedad, 2) la identificación de obras de autor, 3) la delimitación del dominio público, a través del suministro de información relativa a la expiración del derecho de autor, y 4) el mapeo de la actividad creativa dentro de un territorio. ${ }^{3 \mathrm{I}}$ En un estudio, la OMPI reportó que 48 de 186 Estados miembros ${ }^{32}$ administran registros voluntarios dentro de su territorio. ${ }^{33}$ Finalmente, estos sistemas voluntarios de formalidades públicas catalogan sólo una fracción muy pequeña de las obras de autor elegibles. ${ }^{34}$ La gran mayoría de estos sistemas son administrados dentro de la rama ejecutiva del gobierno, usualmente por el Ministerio de Justicia o el Ministerio de Cultura. ${ }^{35}$ Pero algunos Estados pequeños, como Armenia, Mali, Namibia y Eslovenia, delegan la administración de su sistema "público» a las entidades de gestión colectiva u otras entidades privadas. También, Italia y Japón tienen sistemas híbridos. Ambos externalizan el registro de programas de computadora a entidades privadas, y particularmente Italia delega el registro de obras audiovisuales a una entidad de gestión colectiva.

Además de reconocer su coexistencia, y los potenciales beneficios de la interoperabilidad de los sistemas públicos y privados, el estudio de la OMPI preguntó si el registro público de copyright de un Estado miembro se interconecta con cualquier otro sistema de datos de derecho de autor. En la mayoría de los casos, la respuesta es no. Sólo en dos casos, Algeria y Mali, el registro público está interconectado con una base de datos de la entidad de gestión colectiva. Otros ejemplos de interconexión

3 I. OMPI, «Agenda para el Desarrollo», disponible en <http://bit.ly/ICH7M8I >, y "Catalogación y registro del derecho de autor», disponible en <http://bit.ly/sHDCGeM>.

32. OMPI, «Estados miembros», disponible en $<$ http://bit.ly/ILfffP $7>$.

33. OMPI, «Resumen de las respuestas al cuestionario de la OMPI para el estudio sobre sistemas de registro y depósito del derecho de autor», disponible en <http://bit. ly/I GqUpUR>.

34. Por ejemplo, en Estados Unidos, fuera de las millones de fotografías publicadas en Flickr, y de las horas de video subidas a Youtube, sólo 636.527 obras de autor fueron registradas en el año 20I0. United States Copyright Office, Annual Report of the Register of Copyrights, 20Iо, disponible en <http://r.usa.gov/rK9ZPbM>.

35. OMPI, «Resumen de las respuestas al cuestionario de la OMPI para el estudio sobre sistemas de registro y depósito del derecho de autor», referido en nota 33. 
implican vínculos intragubernamentales entre ministerios.

El estudio no preguntó acerca de la interoperabilidad entre los registros públicos de los Estados miembros, aunque sí lo hizo respecto a si éstos le atribuirán un valor jurídico a los registros extranjeros. Asimismo, revela que la posibilidad de interoperabilidad en las bases de datos públicas o privadas de registro digital implicaría recorrer un largo camino. Dieciséis Estados miembros almacenan datos de registro solamente en copias impresas, incluyendo Argentina, Brasil, Italia y Sudáfrica. Al menos otros cinco Estados miembros están transitando hacia un sistema de registro digital. Incluso para los sistemas que almacenan registros digitales, sólo once países permiten el acceso del público a través de internet. Sin embargo, para el presente objetivo, el punto clave es que incluso en el lado ostensiblemente "público» de la balanza de las formalidades, los particulares han delegado la responsabilidad de realizar el registro de derechos de autor.

El estudio también revela el amplio espacio existente para realización de mejoras, al hacer que los sistemas de registro voluntario realicen su función en apoyo de una estructura de transacciones, en torno a obras con derechos de autor. ${ }^{36}$ Una mayor estandarización y otras medidas para promover la interconexión y la interoperabilidad entre las bases de datos de registro público y privado, mejorarán de manera casi segura la eficacia general y el atractivo de estos sistemas, e inducirán a una mayor participación por parte de los propietarios de derechos de autor. ${ }^{37}$

Doctrina reciente también ilumina las oportunidades que deja el marco internacional para reimaginar y revitalizar, tanto las formalidades públicas obligatorias como voluntarias. El marco internacional permite que un Estado miembro imponga formalidades obligatorias en sus

36. Todos los datos precedentes están extraídos desde OMPI, «Resumen de las respuestas al cuestionario de la OMPI para el estudio sobre sistemas de registro y depósito del derecho de autor», referido en nota 33.

37. Sprigman (2004: 545-568) sugiere la necesidad de interoperabilidad a través del derecho de autor y un aumento en las formalidades. 
propios nacionales. ${ }^{38}$ Tal como otros contribuyentes a este volumen ${ }^{39}$ argumentan de manera persuasiva, el marco internacional podría también permitir la imposición de formalidades obligatorias en todos los asignatarios y cesionarios de los derechos del autor (Van Gompel, 2013: I453-I456). En este mismo sentido, las formalidades para mantener derechos protegidos por copyright más allá del mínimo establecido en el Convenio de Berna (cincuenta años después de fallecido el autor), también serían admisibles. ${ }^{40}$ Ahora bien, la cuestión de si las formalidades obligatorias que sirven como condición previa para la disponibilidad de medidas cautelares o de recursos jurídicos mejorados van o no en contra del Convenio de Berna - porque se aplican sólo a los recursos jurídicos en lugar de a los derechos- es una pregunta más contenciosa. ${ }^{4 \mathrm{I}}$

Los desafíos digitales y las oportunidades que alimentan algo del renovado interés en las formalidades del derecho de autor en general, también proporcionan la base para esgrimir un argumento adicional res-

38. Véase, por ejemplo, I7 U.S.C. \$4 I I (a) (20I2), que requiere el registro del derecho de autor antes de iniciar demanda por infracción de derechos derivados de «cualquier obra de Estados Unidos».

39. El autor se refiere al volumen 28, número 3, del Berkeley Technology Law Journal, donde originalmente se publicó, en inglés, el presente artículo. (N. del E.)

40. Véase, por ejemplo, The Public Domain Enhancement Act, H.R. 2601, Io8th Cong., at 6, reintroduced as H.R. 2408, que impone un pequeño impuesto como precio para mantener la protección del derecho de autor más allá del mínimo del Convenio de Berna; véase también The Register's Call for Updates to U.S. Copyright Law: Hearing Before the Subcomm. on Courts, Intellectual Prop., and the Internet of the H. Comm. on the Judiciary, II 3 th Cong. (20I3), declaración de Maria A. Pallante: «Se podría considerar aliviar un poco la presión y parálisis provocada por el largo plazo otorgado al derecho de autor, por ejemplo, revirtiendo obras al dominio público después de un periodo de vida más cincuenta años, salvo que los herederos o sucesores registren sus intereses con la Oficina del Derecho de Autor». Cf. Van Gompel (2013: I444-I447).

4I. Compárese Sprigman (2004: 558): «Sin embargo, los autores que fallan en cumplir con las formalidades de nuevo-estilo y que por consiguiente pierden su derecho previamente existente para excluir, probablemente no son, como categoría, privados de los aspectos relacionados con el 'ejercicio y goce' de los derechos económicos pertenecientes a su copyright», con Ginsburg (2013: I 593): «La prohibición de formalidades del Convenio de Berna requiere que los recursos jurídicos básicos relativos al derecho de autor, como las medidas cautelares y los daños actuales, se mantengan disponibles para autores extranjeros que no han registrado localmente sus obras o emprendido otras medidas declaratorias impuestas de manera local.» 
pecto a las formalidades obligatorias. Las tecnologías digitales ofrecen oportunidades trivialmente fáciles para colocar aviso sobre una obra, o registrar en una base de datos la reclamación de un autor al copyright. Basta un computador y acceso a internet. ${ }^{42}$ Los metadatos pueden preconfigurarse para ser asociados automáticamente con archivos digitales, como un documento generado en Microsoft Word, y la creación de información de cuenta en bases de datos digitales se ha tornado en una condición previa rutinaria para la participación en muchos aspectos de la vida digital. ${ }^{43}$ Estos avances tecnológicos representan un cambio radical en las circunstancias vividas por quienes inspiraron la enmienda para suscribir al Convenio de Berna en I908.

En otros contextos jurídicos, el reconocimiento de estas circunstancias tecnológicas modificadas ha conducido a distintas interpretaciones. Por ejemplo, y según los principios legales tradicionales, usualmente la inacción de una persona no admitiría la constatación de un acuerdo implícito o una licencia implícita, como ocurre en el derecho de autor. ${ }^{44}$ No obstante, al menos una corte encontró que la decisión de un editor web consistente en publicar obras protegidas, olvidando la fácil y trivial formalidad de usar el protocolo robots.txt en los metadatos del sitio web diseñados para evitar que los motores de búsqueda copien el texto con fines de indexar y almacenar en caché dichos datos, sirvió de base para constatar que el editor tenía motores de búsqueda con licencia para copiar, indexar y almacenar en caché los contenidos del sitio web. ${ }^{45}$ El sis-

42. Véase, en general, Farrar (2010) al explicar cómo Microsoft Office automáticamente asocia metadatos con archivos, y las implicaciones legales de este hecho en el contexto de litigios; véase también National Information Standards Organization (2004), que define el concepto de metadatos y se describen sus usos potenciales.

43. National Information Standards Organization (2004).

44. Véase Restatement (second) of Contracts $\$ 69$, cmt. a (I98I): «La aceptación basada en el silencio es excepcional. Comúnmente, un oferente no tiene poder para provocar que el silencio del destinatario opere como aceptación»; véase, por ejemplo, William F. Klingensmith, Inc. v. District of Columbia, 370 A.2d I34 I, I343 (D.C. I977), que definió que el silencio de la parte demandada, en respuesta a una carta para el reembolso de un trabajo, no puede constituir un contrato válido.

45. Véase Field v. Google Inc., 4I 2 F. Supp. 2 d I I06, I I I 6 (D. Nev. 2006); cf. Keane Dealer Servs. v. Harts, 968 F. Supp. 944, 947 (S.D.N.Y. I997), que determinó que el conocimiento y el silencio ante el uso de software por parte del demandado suministró la base para la utilización de una licencia implícita. 
tema de licencias colectivas ampliadas adoptado en los países nórdicos tiene una disposición de exclusión similar, ${ }^{46}$ respecto a la cual algunos han planteado que va en contra del artículo 5.2 del Convenio de Berna. ${ }^{47}$ El profesor Daniel Gervais refuta hábilmente esta cuestión. $4^{8}$

Por analogía, una interpretación dinámica del Convenio de Berna llevaría a la conclusión de que, al menos en los países con acceso expedito a computadoras e internet, una formalidad obligatoria de aviso o registro no debe entenderse como un proceso que busque afectar la capacidad de un autor para ejercer o disfrutar de sus derechos con copyright. ${ }^{49}$ Esto sería especialmente cierto para las formalidades que afectaron el alcance de los derechos o de los medios de impugnación disponibles para un autor, basadas en pasos que podrían ser trivialmente fáciles y comunes de seguir en el entorno digital.

Finalmente, si las formalidades se presentan como obligatorias o voluntarias, estudios recientes ofrecen una nueva mirada de la función de filtrado que éstas pueden realizar..$^{\circ}$

Tradicionalmente, el no cumplimiento de las formalidades ha resultado en la pérdida del derecho de autor (Ginsburg, 2010: 328-332). Sin embargo, las formalidades públicas en Estados Unidos ya filtran los recursos disponibles para los propietarios de derechos de autor en obras

46. Riis y Schovsbo (2010: 474-476) proporcionan una visión general del sistema nórdico de licencias colectivas ampliadas.

47. Riis y Schovsbo (2010: 482-485) expresan algunas posibles preocupaciones sobre la interacción entre el Convenio de Berna y el modelo nórdico; véase también Ficsor (2006: 48), quien argumenta que una disposición de exclusión en las licencias colectivas ampliadas es inconsistente con el artículo 5.2 del Convenio de Berna.

48. Véase Gervais (2010b: 24-27), quien argumenta que no todas las formalidades obligatorias son ilegales bajo el Convenio de Berna; cf. Van Gompel (20I I: 209-2 II), quien concluye que los modelos de exclusión optativa de licencias legales no son formalidades prohibidas.

49. Gracias a mi colega Peter Jaszi por esta sugerencia.

50. En Kable v. Gonzales, la Corte del Noveno Circuito sostuvo que la renovación sirvió como un filtro que dejó pasar algunas obras — sobre todo las que no tienen valor comercial - al dominio público. Junto con las formalidades como el registro y el aviso (que también han sido efectivamente eliminadas), los requisitos de renovación crearon un sistema opt-in de copyright, en el que las protecciones sólo estaban disponibles para los que actuaron afirmativamente para asegurarlas. Cf. Kable v. Gonzales, 487 F.3 697, 699 (9th Cir. 2007). 
del mismo país, ${ }^{5 \mathrm{I}} \mathrm{y}$ este enfoque se podría aplicar creativamente, también para incluir alcance.

Sería especialmente valorable una aproximación más matizada a la función de filtrado, en tanto el copyright automático en el mundo digital ha llevado a una continua y creciente erupción de derechos de autor..$^{52}$ Un lugar útil para empezar en este análisis es el informe del proyecto Principios del Copyright, que sugiere formas en las cuales el alcance y los recursos jurídicos podrían ser adaptados en función de si los titulares de derechos optan por registrar sus reclamos al copyright en un registro digital actualizado (Samuelson y otros, 20I0). Con un sistema de registro fácil puesto en su lugar, la decisión de un creador de no registrarse tendría consecuencias. Específicamente, el informe imagina formalidades que tornarían la protección a un nivel tal, que el alcance del copyright en obras no registradas podría limitarse a la prohibición de realizar copias exactas o casi exactas, que causen daño comercial. Otros usos probablemente se considerarían justos. Los recursos jurídicos relativos a obras sin registrar no incluirían daños estatutarios, o los honorarios de los abogados. En contraste, el registro probablemente proporcione derechos de un alcance más amplio, incluyendo los derechos de excluir la copia de elementos no literales en una obra de autor, y poner fin a algunos de los usos no comerciales que puedan tener efectos de merma de mercado. El derecho de suspender la transferencia del derecho de autor después de un periodo de años, también podría limitarse a los propietarios del copyright en las obras registradas. Un propietario de derechos de autor podría registrarse en cualquier momento, pero los beneficios de tal registro no serían retroactivos (Samuelson y otros, 20IO: I20I).

El debate emergente sobre la reintroducción o mejora de las formalidades públicas es bienvenido. Los avances en tecnologías digitales son tanto la fuente de muchos problemas asociados con la falta de formalidades, así como la fuente potencial de soluciones. En el contexto mo-

5I. Véase I7 U.S.C. $\mathbb{S} 4$ I 2 (20I2).

52. Samuelson y otros (2OIO: I I 86): «El paso a un régimen de protección automática pone a la ley actual en tensión con el principio de que deben existir formas razonables para que el público obtenga información respecto a quién es el dueño de qué derechos y sobre qué obras, y si ellas se encuentran o no disponibles para su uso o están en el dominio público.» Debo señalar que fui miembro de «Copyright Principles Project». 
derno, las formalidades públicas podrían ser diseñadas para evitar las consecuencias excesivamente duras que con tanta frecuencia afectan a un pequeño número de propietarios de derechos de autor, bajo el enfoque histórico del todo-o-nada (Ginsburg, 2010: 328-332). En cambio, el aviso y el registro, y potencialmente la inscripción, depósito o mantenimiento, podrían todos llevarse a cabo para las obras digitales, con escasos problemas para el titular de los derechos.

Las formalidades de nuevos estilos podrían flexibilizarse de variadas formas, incluso estando limitadas a obras en formato digital, y no aplicándose a autores en territorios que actualmente carezcan de acceso rápido y fiable a internet. Dichas formalidades podrían reformar la función pública de recolección y compartimiento de información acerca de trabajos creativos, mejorando las transacciones productivas que benefician por igual a creadores y audiencias. Es importante destacar que las formalidades públicas de nuevos estilos deben ser formadas tanto para interoperar con los sistemas de formalidades privadas — discutidos en la siguiente subtítulo-, como para mejorar su transparencia. La interoperabilidad requeriría acuerdos sobre normas técnicas comunes y sobre el tipo de información que los registros públicos deberían entregar, comparada a la información que debería ser tratada como comercial y demasiado sensible para ser hecha pública. Un diseño trataría el depósito/ registro público como la capa base de información, que entonces podría ser extendida para su uso en sistemas privados de formalidades, como las entidades de gestión colectiva.

\section{REGULANDO LAS FORMALIDADES PRIVADAS}

La narrativa del derecho de autor que se hace cargo de las formalidades, ignora el hecho de que la proscripción de formalidades públicas obligatorias en la Unión de Berna, a principios del siglo XX, coincidió con la aparición de las entidades de gestión colectiva (Gervais, 2orob: 3-Io). Estas entidades de gestión colectiva trajeron consigo la aparición de requerimientos formales administrados privadamente, para que los autores proporcionen información relevante como condición de recibir una parte de los beneficios económicos administrados por las entidades. Así las cosas, sería mejor entender la historia de la «muerte de las formalidades» no tanto como una victoria filosófica para el derecho de autor, 
sino como una historia de privatización o externalización acerca de la administración de un sistema de copyright.

Desde esta perspectiva, la reform(aliz)ación de los derechos de autor significa que la actual política pública debe reclamar un papel más decisivo en el establecimiento, administración o regulación de los sistemas de formalidades de derechos de autor nuevos y existentes. El trabajo realizado en este sentido llama la atención hacia las formalidades administradas privadamente, a su interacción con los sistemas administrados de manera pública, y al «escenario internacional altamente asimétrico» creado por esta interacción..$^{53}$ Por ejemplo, un proyecto en apoyo de la Agenda de la OMPI para el Desarrollo ${ }^{54}$ ilustra la oportunidad política de usar formalidades de copyright públicas y privadas para promover el acceso a obras "huérfanas», y a obras en el dominio público del derecho de autor. ${ }^{55}$

Siendo ya un hecho que los sistemas de formalidades administradas privadamente ocupan gran parte del terreno, los políticos deberían enfocar su atención al grado en que estos sistemas son interoperables, transparentes y efectivos.

Hasta hace poco tiempo, estos sistemas privados han estado sujetos a muy poca o ninguna supervisión pública. ${ }^{56}$ Esta falta de supervisión está comenzando a cambiar, específicamente respecto a la transparencia de las entidades de gestión colectiva. ${ }^{57}$ Los funcionarios públicos pue-

53. Véase OMPI, «Catalogación y registro del derecho de autor», referido en nota I7, donde se describen estudios sobre sistemas públicos y privados de catalogación y registro, como parte del trabajo en el proyecto temático denominado «La propiedad intelectual y el dominio público».

54. La Agenda de la OMPI para el Desarrollo se refiere a un paquete de 45 propuestas adoptadas por la Asamblea General de la OMPI en 2007. Cf. OMPI, «Catalogación y registro del derecho de autor», referido en nota 17.

55. Véase OMPI, «Agenda para el Desarrollo», referido en nota 3 I, y «Catalogación y registro del derecho de autor», referido en nota 17.

56. Véase la «Propuesta de Directiva del Parlamento Europeo y del Consejo sobre Gestión Colectiva del Derecho de Autor y Derechos Relacionados y Licenciamiento Multiterritorial de Derechos en Obras Musicales para Usos en Línea en el Mercado Interno", artículo I 8, disponible en <http://bit.ly/Ie4 $\mathrm{QF}_{4} \mathrm{~K}>$; Lorrain (20I3) analiza los problemas de transparencia en la directiva y al propone sugerencias. Cf. también Gervais (20Iob: I4-I8).

57. Acogerse al acuerdo de Santiago, que requirió a las entidades de gestión colectiva el reporte de cierta información, fue un "paso en la dirección correcta, [aunque] estuvo plagado de complejos problemas prácticos y legales» (Woods, 2009: I I 5 5-I I 57). 
den y deberían hacer más para asegurar una mejor integración entre los sistemas de formalidades públicas y privadas, y para asegurar que estos sistemas funcionen en pos de servir al interés público final que el derecho de autor tiene como objetivo promover. En lo que sigue graficamos estos sistemas de formalidades privadas, y luego esbozamos una estrategia de política pública para mejorar su funcionamiento dentro de la creciente economía del copyright.

\section{A. UNA REVISIÓN DE LOS SISTEMAS DE FORMALIDADES PRIVADAS}

Los sistemas de formalidades administradas privadamente son heterogéneos, pero a grandes rasgos se clasifican en tres grupos: I) registros y sistemas relacionados, administrados por organizaciones que pueden ser dueñas de derechos protegidos por copyright -o derechos relacionados- o, más comúnmente, que actúan como agentes transaccionales para los titulares; 2) registros de terceros o servicios de catalogación para los derechos de autor, que no dependen únicamente de la contribución de los titulares para recopilar y organizar información acerca de las obras de autor y sus respectivos titulares (por ejemplo, el registro Content ID de Youtube); y 3 ) organizaciones que compiten directamente con los sistemas de formalidades públicas para proveer servicios de catalogación de copyright a los titulares, tales como el aviso (por ejemplo, marcas de agua), registro o depósito.

\section{Formalidades administradas en apoyo de la representación de un titular}

Los longevos y, hasta hace poco, más económicamente importantes sistemas de formalidades privadas son aquellos administrados por las entidades de gestión colectiva. Estas entidades tienen autoridad legal para conceder licencias o cobrar regalías en nombre de los autores u otros titulares de derechos. Aunque se podría sostener que las organizaciones de gestión colectiva originales fueron los gremios venecianos o la Stationers' Company, estos grupos, como colectivos de autores propiamente tales, se originaron en Francia en el siglo XVIII (Gervais, 20 Iob: 6-10).

Los autores tienen en general la posibilidad de elegir si desean registrarse en una entidad de gestión colectiva, aunque en algunos países la 
afiliación es obligatoria. ${ }^{8}$ Para hacerse parte del registro de la entidad y recibir las regalías provenientes de ella, un autor debe proporcionar su identificación y una mínima información de contacto. El autor puede suministrar información sobre las obras presentadas al repertorio de la entidad, o bien, aquélla puede ser recopilada de manera independiente por los mismos empleados de la organización. Luego, la entidad compara estos datos con los datos de uso para compensar a los titulares (Gervais, 20Iob: 8).

Al representar derechos en un repertorio de obras, las entidades de gestión colectiva comúnmente operan de manera territorial, y tienen menos facultades que las que proporcionaría el conjunto completo de derechos exclusivos en una obra de autor. ${ }^{59}$ En consecuencia, dentro de un territorio específico, más de una entidad podría tener interés en una obra determinada, lo que es especialmente cierto en los territorios (Gervais, 20Iob: 6-8). En consecuencia, las entidades de gestión colectiva se dedican a la cooperación transfronteriza, a través de acuerdos de representación recíproca (Gervais, 20ıob: 7), y al federarse en organizaciones paraguas. Las más grandes de estas organizaciones son la Confederación Internacional de Sociedades de Autores y Compositores (CISAC), que federa a 23 I entidades en I I países, para representar los intereses de más de tres millones de creadores y titulares de derechos, ${ }^{60}$ y la Federación Internacional de Entidades de Gestión de Derechos de Reproducción (IFRRO). ${ }^{6 \mathrm{I}}$

Los sistemas de formalidades privadas de estas organizaciones apoyan a una estructura de transacciones sustancial. En 20I0, las organizaciones miembro de la CISAC recaudaron 7.545 millones de euros, la mayoría provenientes de la concesión de licencias de derechos de ejecución pública. A diferencia de algunos de los sistemas de formalidades públicas descritos en la segunda parte de este artículo, los miembros de la CISAC

58. OMPI, «Resumen de las respuestas al cuestionario de la OMPI para el estudio sobre sistemas de registro y depósito del derecho de autor», referido en nota 33.

59. Gervais (20I0b: 6-8); véase también Dusollier y Colin (20 I I: 8 I 8-820), quien esboza los límites de las entidades de gestión colectiva y los diferentes tipos; Bonadio (20I 2: 2-3) discute sobre el sistema de licencias colectivas en la industria musical internacional.

6o. Véase $<$ http://www.cisac.org $>$.

6I. Véase <http://www.ifrro.org $>$. 
invirtieron una energía considerable en el uso de tecnología digital para perfeccionar el intercambio de información relacionada con las transacciones entre organizaciones miembro. En un informe a la OMPI, un consultor de la CISAC detalló la adopción de normas técnicas — por parte de la CISAC - para la identificación de autores, titulares de derechos, obras de autor y de datos de transacción relevantes para automatizar el intercambio de información entre las organizaciones miembro (Nutall, 20I I). Como resultado, la CISAC desarrolló CIS-Net, el producto de un ciclo de desarrollo de diez años para mejorar la estandarización e interoperabilidad entre los respectivos sistemas de formalidades privadas de las organizaciones miembro. ${ }^{62}$

Esta actividad de desarrollo de estándares se llevó a cabo sin ningún tipo de coordinación significativa con los administradores del sistema de formalidades públicas, ni con desarrollos paralelos de estándares por parte de otros administradores privados de sistemas de formalidades. ${ }^{63}$ Por ejemplo, un problema común a todos los sistemas de formalidades es determinar cómo eliminar la ambigüedad de aquellas partes que tengan los mismos nombres, o nombres muy similares. Para resolver esta situación, en lugar de adoptar un procedimiento único a través de las plataformas, los desarrolladores de CIS-Net eligieron una solución, ${ }^{64}$ en tanto que el proyecto ORCID para la desambiguación de identidades de autores de investigación, adoptó una diferente. ${ }^{65}$ Afortunadamente,

62. Nutall (20II: 30) afirma: «En el año 2000, un cierto número de Sociedades de Autores crearon 'FastTrack', una alianza técnica enfocada en la creación de una red, conectando los nodos de documentación claves para mejorar el flujo de datos y el intercambio de información. En el 2005, FastTrack GDDN (Catalogación Global y Red de Distribución) se expandió a todos los miembros de la CISAC y se rebautizó como 'CIS-Net potenciada por FastTrack'. CIS-Net es ahora la columna vertebral de todo el intercambio de Documentación de Obras Musicales».

63. Nutall (2OI I: 30) demuestra que el desarrollo de CIS-Net se llevó a cabo sin coordinación con los administradores de los sistemas de formalidades públicas.

64. Nutall (2OII: 3 I-32) discute el uso que CIS-Net hace de la base de datos Interest Party Information y del Índice de Búsqueda Común para proporcionar códigos únicos.

65. Véase "Qué es ORCID», en el sitio web de ORCID, disponible en <http://bit. ly/IKb89Io>: «ORCID es un proyecto abierto, sin ánimo de lucro, comunitario, que ofrece un sistema para crear y mantener un registro único de investigadores y un método claro para vincular las actividades de investigación y los productos de estos identificadores.» 
tanto CIS-Net como ORCID utilizan protocolos abiertos que posibilitan la interoperabilidad, ${ }^{66}$ pero al precio de un procesamiento adicional que posiblemente se pudo haber evitado. El punto más profundo de esto es que la posición natural y por defecto para los administradores de sistemas de formalidades privadas, es modelar soluciones propias para los problemas más comunes, en vez de absorber los costos de coordinarse con otros administradores en dominios aparentemente sin relación. Si este enfoque está en el interés público — respecto al funcionamiento general de la estructura de transacciones de derechos de autor- es una cuestión que merece la atención de los funcionarios públicos.

\section{Terceros depositarios y registros: El estudio del caso de Youtube}

Muchas discusiones relativas a las formalidades de copyright comparten la premisa implícita de que el autor o titular debe suministrar información o realizar ciertas acciones para cumplir con las formalidades. Han surgido algunos ejemplos de situaciones híbridas, basadas, por una parte, en la aportación de un titular, y, por la otra, en los datos generados por el administrador del sistema de formalidades privado.

La versión de este fenómeno con mayor importancia económica es el sistema Content ID de Google, usado por Youtube tanto para actividades de observancia como de transacción. ${ }^{67}$ Los titulares proporcionan archivos de referencia (depósito), metadatos sobre estos archivos (registro) y políticas sobre qué quieren que Youtube haga si encuentra una coincidencia entre el archivo de referencia y un archivo subido por algún usuario (inscripción, al menos para las políticas que permiten el otorgamiento de licencias).

Youtube crea un hash, un identificador digital único, para cada archivo de referencia, y luego ejecuta los videos subidos a través de un algoritmo que busca hacer coincidir el patrón de datos codificado en el hash, con los datos en el archivo subido. Según la página web de Youtube, la

66. Nutall (20I I: 8-9). Cf. ORCID, «Open Source Project Now Available!», disponible en <http://bit.ly/ILqA 3 ld >, donde se explica la decisión de liberar el código fuente para mejorar la interoperabilidad con servicios externos.

67. «Cómo funciona Content ID», Ayuda de Youtube, disponible en <http://bit. ly/I Gqtdpc $>$. 
base de datos de Content ID tiene más de quince millones de archivos de referencia, que son comparados con más de 250 años de video que Content ID escanea diariamente. ${ }^{68}$ Más de un tercio de las «vistas monetizadas» de Youtube derivan de coincidencias de Content ID. ${ }^{69}$

Aunque este artículo se ha centrado en el papel de los registros en un sistema de formalidades, el aviso y el depósito son también funciones que realizan los sistemas de formalidades privadas. Youtube es un depositario, tanto por su programa Content ID, como por ser un lugar en el que los titulares ponen su contenido a disposición. A pesar de que existen otras opciones para compartir video en internet, la enorme audiencia de Youtube sin duda lo hace necesario para que ciertos autores o titulares depositen una copia de sus obras audiovisuales, con el fin de disfrutar o ejercer plenamente sus derechos protegidos por copyright. De manera adicional, el hash de Content ID funciona como una forma de aviso automatizado. Aunque en la actualidad Youtube utiliza de manera interna el hash de Content ID, dicho aviso automatizado podría usarse o ser invocado por otras partes si estos datos estuviesen disponibles de manera pública.

El registro de Content ID funciona como parte de un sistema de formalidades privadas, en tanto Youtube ofrece a los titulares la oportunidad de dar el paso formal de contactarse con él, proporcionando sus datos de identidad y contacto, y suscribiendo un acuerdo de compensación. Este paso formal es una condición previa necesaria para que un titular participe de los ingresos generados por ciertos usos de Content ID.

Es posible que otras plataformas dependientes de publicidad, basadas en el contenido generado por el usuario - como Pinterest - tengan también interés en desarrollar registros de contenido de la misma forma que Youtube, y con los mismos fines. También es probable que esos desarrollos se produzcan sin ninguna coordinación apreciable ni la vigilancia de funcionarios públicos, incluyendo los administradores de sistemas de formalidades públicas. Los titulares de derechos, y cualquier parte interesada, deben esperar a que terceros adicionales, como Youtube, usen esas tecnologías digitales para generar bases de datos de obras de autor.

68. Estadísticas de Youtube, disponible en <http://bit.ly/IJn 5 isS $>$.

69. «History of Content Management», Youtube 5 Year, disponible en <http://bit. ly/ıghzSH>. 
Aquellos terceros no necesitarán, y probablemente ni siquiera busquen, la participación de los titulares. Por otra parte, los titulares también pueden esperar que sea necesario un paso formal para recibir el beneficio de los ingresos generados por estas bases de datos. Este procedimiento ha sido utilizado para generar bases de datos de redes sociales de terceros, y no hay razón para pensar que no se podrían usar las mismas técnicas para crear bases de datos de derechos de autor (Sorkin, 20I3: BI).

\section{Registros privados}

Por último, una serie de empresas privadas han percibido un vacío en el mercado de registro voluntario y servicios de depósito. ${ }^{7 \circ}$ Como lo demuestra el estudio de sistemas de formalidades públicas patrocinado por la OMPI, ciertos países no ofrecen servicios de registro administrados públicamente, y sólo una pequeña porción de aquéllos pone sus registros a disposición en internet. ${ }^{7 \mathrm{I}}$ En la búsqueda de competir directamente con los sistemas voluntarios públicos, o de complementarlos, estos servicios — principalmente digitales-, llenan los vacíos en los sistemas públicos al aceptar depósitos de cualquier territorio, en formatos múltiples, y a precios que permiten el registro de los trabajos generados por los usuarios. También utilizan tecnologías digitales, incluyendo el uso de hash, para identificar a los titulares y a las obras (Ricolfi y otros, 20I I: I 8-2I).

La OMPI encargó un estudio de estos servicios de catalogación privada para graficar el estado actual de este mercado emergente. El estudio recabó que un rango de registros de propósito general hizo ingreso al mercado (Ricolfi y otros, 20I I: I 8-2I). Algunos de estos registros se dirigen a usuarios de licencias Creative Commons, ${ }^{72}$ quienes podrían estimar útil el registro para apoyar el requerimiento de atribución en dichas licencias (Ricolfi y otros, 20II: I 8-2I). Entre otros de los objetivos de

70. Ricolfi y otros (20I I : 4-7) describen el estudio de la OMPI centrándose en la aparición de dichos servicios como respuesta al vacío percibido en el mercado.

7I. Véase OMPI, «Resumen de las respuestas al cuestionario de la OMPI para el estudio sobre sistemas de registro y depósito del derecho de autor», referido en nota 33 , donde se describe la falta de capacidad digital y de red para la mayoría de los sistemas de formalidades públicas.

72. Cabe mencionar que este autor es miembro de la Junta Directiva de Creative Commons. 
los registros de propósito general, cabe mencionar la entrega de servicios específicos de dominio, como ocurre con el Registro Oeste del Gremio de Escritores de América.73

Debido a que en muchos países la ley otorga valor probatorio u otro efecto legal a la participación en sistemas de formalidades públicas, ${ }^{74}$ los sistemas privados se mantienen en una desventaja competitiva respecto a ciertas clases de titulares. Con todo, la proliferación continua de estos servicios sugiere que existe una demanda latente lo suficientemente percibida, que hace muy probable que estos sistemas persistan. A pesar de que en este punto de la era digital podría desearse algún nivel de competencia -incluso normada-, esta misma llevó a una situación en la que sistemas de formalidades privadas fragmentados y no interoperables, fallan al proporcionar muchos de los beneficios públicos que podrían lograrse a través de una mayor interoperabilidad y transparencia. ${ }^{75}$

\section{B. RESPUESTAS GUBERNAMENTALES QUE SE HAN PROPUESTO}

Este estudio acerca de las formalidades privadas demuestra que la prohibición contenida en el artículo 5.2 del Convenio de Berna no eliminó los requerimientos formales para que los autores ejerzan o gocen en conjunto sus derechos protegidos por copyright, sino que más bien reubicó estas formalidades hacia el sector privado. Este cambio de perspectiva apoya un mayor nivel de colaboración con los sistemas de formalidades

73. Cf. Ricolfi y otros (20 I : 23-24). Véase, en general, Fisk (20 I I: 267-274) al explicar y proporcionar las razones para el registro de copyright de los guionistas.

74. Véase OMPI, «Resumen de las respuestas al cuestionario de la OMPI para el estudio sobre sistemas de registro y depósito del derecho de autor", referido en nota 33, pág. 5. Véase también Ricolfi y otros (20I I: 4I-43), quienes señalan las ventajas legales que gozan los sistemas de formalidades públicas voluntarias por sobre los sistemas de documentación privada.

75. Ricolfi y otros (20II: I 8) afirman: "Como cuestión de hecho, es difícil para los usuarios buscar más de un registro único de derechos de autor a la vez, y el número de búsquedas necesarias para descartar que una obra ha sido registrada en alguna parte, crece con el número de registros. Por otra parte, la investigación realizada para este estudio demuestra claramente que incluso encontrar los registros mismos podría ser un reto, sobre todo si se trató de encontrar a todos ellos, y no sólo los más populares. Por lo tanto, la fragmentación del registro genera costes adicionales para los usuarios». 
privadas al hacer que los funcionarios públicos aseguren que los objetivos finales de política pública del derecho de autor están siendo atendidos por estas formalidades privadas.

La colaboración de los funcionarios públicos debería ser de amplio alcance. Debería incluir la introducción de cierta regulación formal, como también el uso del poder de convocatoria del gobierno. Este poder podría centrar su atención en encontrar soluciones para problemas comunes, y podría estimular la participación en asociaciones público-privadas para aumentar la interoperabilidad entre los sistemas de formalidades públicas y privadas. ${ }^{76}$ Para atender los fines generales de las formalidades en la economía del copyright, los funcionarios públicos deberían centrar sus esfuerzos en mejorar la efectividad de las formalidades de dos modos. Primero, deberían fomentar transacciones socialmente benéficas relativas a obras de autor, tanto comerciales como no comerciales. En segundo lugar, deberían buscar reducir las fricciones causadas producto de la existencia de copyrights automáticos y duraderos, ya sea filtrando conjuntamente algunas obras fuera del sistema o a través de la reducción de los costos sociales de derechos de autor cuyos titulares tienen poco o ningún interés en utilizar productivamente.

Esta meta consistente en mejorar la efectividad de las formalidades se puede lograr de una mejor manera aumentando la interoperabilidad entre los sistemas de formalidades e incrementando su transparencia. Aquí, ésta tiene dos significados. Uno es hacer pública mucha de la información en poder de los sistemas de formalidades privadas. El segundo es aumentar la rendición de cuentas de los procedimientos de operación internos de quienes administran dichos sistemas. ${ }^{77}$ Estas metas secundarias

76. Este enfoque tiene mayor aceptación general en Estados Unidos. Véase, por ejemplo, Chopra y Gallagher (2OI2): «La administración reconoce la importancia de que el Gobierno Federal trabaje con el sector privado para hacer frente común a las necesidades de estandarización, y de adoptar tanto un rol organizacional como de compromiso activo cuando sea necesario para garantizar una respuesta rápida y coherente a los desafíos nacionales».

77. Véase, por ejemplo, que el gobierno de Países Bajos anunció mayor supervisión a las entidades de gestión colectiva de derechos de autor, a partir del I de julio de 20I4, a las cuales se exigirá revelar públicamente «las tarifas, condiciones de licencia, programas de descuento, costos de administración y las posiciones adicionales de [sus] gestores». Disponible en <http://bit.ly/ICLJvOx>. 
apuntan a suministrar liquidez informacional para el mercado, para las transacciones relacionadas con obras protegidas por derechos de autor. También deben aumentar la eficiencia administrativa, proporcionando más valor para ser compartido entre los productores y usuarios de estos trabajos.

Al promocionar la interoperabilidad, los funcionarios públicos deberían buscar incentivar la innovación en el uso de tecnologías digitales para mejorar el funcionamiento de los sistemas de formalidades de copyright. Con el uso de su poder de convocatoria, el gobierno podría reunir a los administradores más visionarios para identificar los estándares que mejor realicen las funciones que requiere un sistema de formalidades. Por ejemplo, se invirtió una gran cantidad de pensamiento creativo y energía en la creación del CIS-Net y los registros privados para propósitos generales, y podría realizarse una convocatoria pública para evaluar si estos estándares se pueden generalizar para otros usos. Donde la estandarización sea demasiado difícil de conseguir, los funcionarios públicos deberían considerar seriamente el uso de su poder reglamentario para requerir o incentivar fuertemente que los estándares de competencia se ajusten para lograr la interoperabilidad.

En un sentido similar, los funcionarios públicos deberían procurar entrar en asociaciones con administradores de sistemas de formalidades privadas, para lograr la interoperabilidad entre los sistemas públicos y privados de formalidades. En este punto, el concepto de extensibilidad es esencial. La función de los sistemas de formalidades públicas es probablemente más limitada que la de muchos de los sistemas privados. Tendría sentido para los sistemas públicos que se provea de una capa base de información, la que podría entonces ser fácilmente extendida para incluir metadatos adicionales acerca de obras de autor, autores, titulares de derechos, y de otros con un interés jurídicamente reconocible en obras de autor.

No obstante, la regulación no se puede evitar. Las prácticas de las entidades de gestión colectiva requieren una mayor supervisión pública. $7^{7}$

78. Véase, por ejemplo, Guibault y Van Gompel (2010: I65-167) que afirman: «En resumen, la gestión colectiva de los derechos en el ámbito europeo se encuentra en un estado de caos. En lugar de cooperar a través de acuerdos bilaterales para optimizar la concesión de licencias de derechos de autor a nivel internacional, como anteriormente 
Algunas de las cuestiones más problemáticas no siempre se vinculan a las funciones de estas entidades como administradoras de sistemas de formalidades privadas, pero incluso cuando los problemas se derivan de ello, éstos son a menudo agravados e instigados por la ausencia de interoperabilidad y transparencia en la administración de los sistemas de formalidades privadas. ${ }^{79}$ Los funcionarios públicos ya han empezado a responder. La Comisión Europea ha propuesto un proyecto de Directiva que regula a las entidades de gestión colectiva que administran derechos en obras musicales. ${ }^{80}$ Se podría hacer más para lograr que los datos en poder de los sistemas de formalidades privadas de estas entidades sean más públicos. En suma, una vez que se reconoce que las formalidades están vivas y presentes en el sistema de derechos de autor -mediante estos sistemas de formalidades privadas- siguen una serie de respuestas públicas razonables, como la descrita anteriormente.

\section{CONCLUSIÓN}

Construyendo sobre la literatura emergente relacionada con una reformalización del derecho de autor, el principal objetivo de este artículo es sugerir que tal reformalización debe ser vista como un esfuerzo por recuperar las formalidades desde el control privado exclusivo. Esto permitiría que las formalidades sirvan mejor al propósito público del derecho de autor, consistente en proporcionar beneficios públicos en vez de resucitar reglas de copyright enterradas por el Convenio de Berna (a partir de 1908) y el Acuerdo sobre los ADPIC. Las formalidades privadas tienen su lugar, y en el entorno digital, deberían diseñarse formalidades públicas revitalizadas y reinventadas para interoperar con sistemas de formalidades privadas. Finalmente, este artículo también ofrece apoyo

lo hicieron, las entidades de gestión colectiva nacionales en Europa están involucradas en litigios para prevenir que cualquiera de ellas expida licencias paneuropeas de sus respectivos repertorios».

79. Band (20I2) proporciona ejemplos sobre cómo las entidades de gestión colectiva han sido mal administradas y carecido de transparencia.

80. Véase Directiva del Parlamento Europeo y del Consejo sobre Gestión Colectiva del Derecho de Autor y Derechos Relacionados y Licenciamiento Multiterritorial de Derechos en Obras Musicales para Usos en Línea en el Mercado Interno, referida en nota 54 . 
adicional para aquéllos que argumentan que las restricciones impuestas por el artículo 5.2 del Convenio de Berna y su incorporación en el Acuerdo sobre los ADPIC a través del artículo 9.I, dejan espacio para que los gobiernos nacionales sean mucho más creativos en el uso de las formalidades, respetando, sin duda, a los autores nacionales y a los cesionarios de todas las nacionalidades.

\section{REFERENCIAS}

Austin, Graeme W. (2005). «Symposium: Metamorphosis of artists' rights in the digital age». Columbia Journal of Law \& the Arts, 28 (4): 397-4 I 8 .

BAND, Jonathan (20I2). "Cautionary tales about collective rights organizations». Disponible en <http://ssrn.com/abstract=2 I 49036>.

Bonadio, Enrico (2OI2). "Collective management of music copyright in the internet age and the EU initiatives: From reciprocal representation agreements to open platforms». En World Library and Information Congress: 78 th IFLA General Conference and Assembly, disponible en $<$ http://bit.ly/ıOktosB>.

Carroll, Michael W. (2006). «One for all: The problem of uniformity cost in intellectual property law». American University Law Review, 55:845-900.

Chopra, Aneesh y Patrick Gallagher (20I2). "Public-private standards efforts to make America strong». The White House. Disponible en <http://1.usa.gov/1JnuPlJ>.

Cohen, Felix (1935). «Transcendental nonsense and the functional approach». Columbia Law Review, 35 (6): 809-849.

De la Durantaye, Katharina (20II). "Finding a home for orphans: Google Book Search and orphan works law in the United States and Europe». Fordham Intellectual Property, Media and Entertainment Law Journal, 2I (2): 229-29I.

Dusollier, Séverine (2OII). «(Re)Introducing formalities in copyright as a strategy for the public domain». En Lucie Guibault y Christina Angelopoulos (editores), Open content licensing: From theory to practice. Amsterdam: Amsterdam University Press.

Dusollier, Séverine y Caroline Colin (2OI I). «Peer-to-peer file sharing 
and copyright: What could be the role of collective management?». Columbia Journal of Law \& the Arts, 34 (4): 809-835.

FARrAR, Randall (20I0). "Metadata: The hidden disaster that's right in front of you». New York State Bar Association Journal, October: 4952. Disponible en <http://bit.ly/1HBQ6Ia>.

FICSOR, Mihály (2006). "Collective management of copyright and related rights in the digital, networked environment: Voluntary, presumption-based, extended, mandatory, possible, inevitable?». En Daniel Gervais (editor), Collective management of copyright and related rights. The Netherland: Kluwer Law International.

-. (20I0). «Collective management of copyright and related rights from the viewpoint of international norms and the acquis communautaire». En Daniel Gervais (editor), Collective management of copyright and related rights. The Netherland: Kluwer Law International.

FISK, Catherine (20II). "The role of private intellectual property rights in markets for labor and ideas: Screen credit and the writers guild of America, I938-2000». Berkeley Journal of Employment and Labor Law, 32 (2): 21 5-278.

Gervais, Daniel (2010a). «The I 909 Copyright Act in international context». Santa Clara High Technology Law Journal, 26 (2): I 8 5-2I 4.

-. (20IOb). "Collective management of copyright: Theory and practice in the digital age». En Daniel Gervais (editor), Collective management of copyright and related rights. The Netherland: Kluwer Law International.

-. (20II). "The Google Book Settlement and the TRIPS Agreement». Stanford Technology Law Review, I: I-IO.

Gibson, James (2005). "Once and future copyright». Notre Dame Law Review, 8I (I): I67-245.

Ginsburg, Jane C. (20I0). "The U.S. experience with mandatory copyright formalities: A love/hate relationship». Columbia Journal of Law of the Arts, 33 (4): 3 I I-344.

-. (2013). "With untired spirits and formal constancy: Berne-compatibility of formal declaratory measures to enhance title-searching». Berkeley Technology Law Journal, 28 (3): I 583-I622.

Glushro Samuelson Intellectual Property Law Clinic (2005). Respuesta al aviso de indagación sobre el problema de las «obras 
huérfanas» realizado por United State Copyright Office, Library of Congress. Disponible en <http://1.usa.gov/1Hzs8zi>.

Guibault, Lucie y Stef van Gompel (2010). «Collective management in the European Union». En Daniel Gervais (editor), Collective management of copyright and related rights. The Netherland: Kluwer Law International.

Натсн, Orrin G. (1989). «Better late than never: Implementation of the I 886 Berne Convention». Cornell International Law Journal, 22 (2): I7I-I95.

Helfer, Laurence R. (20IO). "Collective management of copyrights and human rights: An uneasy alliance revisited». En Daniel Gervais (editor), Collective management of copyright and related rights. The Netherland: Kluwer Law International.

Horwitz, Morton J. (I982). «The history of the public/private distinction». University of Pennsylvania Law Review, I30: I423-I428.

KARP, Irwin (I995). "A future without formalities». Cardozo Arts \& Entertainment Law Journal, I3: 52 I-258.

Kennedy, Duncan (1982). "The stages of the decline of the public/ private distinction». University of Pennsylvania Law Review, I30: I349-I357.

LEITER, Brian (20I0). "Legal formalism and legal realism: What is the issue?». Legal Theory, I 6 (2): I I I-I33.

Lessig, Lawrence (2004). Free culture. Nueva York: Penguin Press.

Levine, Arthur (I995). "The end of formalities: No more second-class copyright owners». Cardozo Arts \& Entertainment Law Journal, I3: 553-557.

Lorrain, Anne-Catherine (2013). "EU Presidency proposes compromise on draft directive on collective management of copyright», Communia, 22 de mayo de 20I3, disponible en <http://bit.ly/ıOjYBfH $>$.

National Information Standards Organization (2004). Understanding metadata. Disponible en <http://bit.ly/IHWdcsf $>$.

Nutall, Fracois Xavier (20II). Private copyright documentation systems and practices: Collective management organizations' databases (Preliminary version). Disponible en <http://bit.ly/IKbyNRm>.

Pallante, Maria A. (2013). "The curious case of copyright formalities». Berkeley Technology Law Journal, 28 (3): I4I 5-I 423. 
-. (2013). The register's call for updates to U.S. Copyright Law: Hearing before the subcomm. on courts, intellectual prop., and the internet of the H. Comm. on the Judiciary, I I 3 th Cong. Disponible en $<$ http://1.usa.gov/1DlpREa>.

Perlmutter, Shira (1995). «Freeing copyright from formalities». Cardozo Arts \& Entertainment Law Journal, I3: 565-588.

Quevedo, Steven M. (I985). «Comment, formalist and instrumentalist legal reasoning and legal theory». California Law Review, 73 (I): II9-I 57 .

Ricketson, Sam y Jane C. Ginsburg (2006). International copyright and neighbouring rights: The Berne Convention and beyond. Nueva York: Oxford University Press.

Ricolfi, Marco y otros (20II). Survey of private copyright documentation systems and practices. Disponible en $<\mathrm{http}$ ://bit.ly/ICMqOdr $>$.

RiIs, Thomas y Jens SсHоvsвo (2010). «Extended collective licenses and the Nordic experience: It's a hybrid but is it a Volvo or a lemon?». Columbia Journal of Law \& the Arts, 33 (4): 47 I-498.

SAmuelson, Pamela y otros (20I0). "The copyright principles project: Directions for reform». Berkeley Technology Law Journal, 25 (3): I I75-I 245 .

SeIdman, Louis Michael (I984). "Soldiers, martyrs, and criminals: Utilitarian theory and the problem of crime control». Yale Law Journal, 94 (2): 3 I 5-349.

Sorkin, Andrew Ross (20I3). "A database of names, and how they connect». New York Times, I 2 de febrero, pág. BI.

Sprigman, Christopher (2004). "Reform(aliz)ing copyright». Stanford Law Review, 57: 48 5-568.

-. (2013) «Berne's vanishing ban on formalities». Berkeley Technology Law Journal, 28 (3): I 563 -I 582.

StAnton, Susan (I990). «Development of the Berne International Copyright Convention and implications of United States adherence». Houston Journal of International Law, I3 (I): I49-I77.

Turkel, Gerald (i988). "The public/private distinction: Approaches to the critique of legal ideology». Law and Society Review, 22 (4): $80 \mathrm{I}-823$.

VAN Gompel, Stef (2010). «Les formalités sont mortes, vive les formalités! Copyright formalities and the reasons for their decline in 
Nineteenth Century Europe». En Ronan Deazley y otros (editores), Privilege and property: Essays on the history of copyright. Cambridge: Open Book Publishers.

Van Gompel, Stef (20II). Formalities in copyright law. The Netherlands: Kluwer Law International.

Van Gompel, Stef (2013). "Copyright formalities in the internet age: Filters of protection or facilitators of licensing». Berkeley Technology Law Journal, 28 (3): I425-I 458.

Woods, Tanya M. (2009) «Working toward spontaneous copyright licensing: A simple solution for a complex problem». Vanderbilt Journal of Entertainment and Technology Law, I I (4): I I 4 I-I I 68.

\section{SOBRE EL AUTOR}

Michael W. Carroll es profesor de derecho y director del Program on Information Justice and Intellectual Property, American University, Washington College of Law. Su correo electrónico es <mcarroll@wcl. american.edu> y su dirección postal: 480 I Massachusetts Avenue N.W. Washington, DC 20016.

Este artículo fue publicado originalmente en Berkeley Technology Law Journal vol. 28, núm. 3, de 20I3, bajo el título «A realist approach to copyright law's formalities» y ha sido traducido al castellano por Máximo Saavedra Díaz, alumno ayudante del Centro de Estudios en Derecho Informático de la Facultad de Derecho de la Universidad de Chile, conforme los términos de la licencia Creative Commons Atribución 4.0 utilizada por el autor. 